\title{
Effect of Oxygen Concentration on the Carbon Monoxide Yields from Methane and Methanol Flames
}

\author{
YUKO SASO, HIROSHI GOTODA, and YOSHIO OGAWA \\ National Research Institute of Fire and Disaster \\ 3-14-1 Nakahara, Mitaka, Tokyo 181-8633, Japan
}

\begin{abstract}
Reduced oxygen concentration environment by diluting with nitrogen $\left(\mathrm{N}_{2}\right)$ is expected as one of the alternative fire prevention and extinguishing technologies. To ensure the fire safety under reduced oxygen concentration, it is necessary to explore the carbon monoxide (CO) production because $\mathrm{CO}$ is known as a major cause of fatalities in compartment fire. To reveal the $\mathrm{CO}$ production in gaseous and liquid combustion under reduced oxygen concentration, the $\mathrm{CO}$ yield under oxygen-reduced condition was investigated experimentally using a cup burner. $\mathrm{CH}_{4}$ and $\mathrm{CH}_{3} \mathrm{OH}$ were used as fuels and supplied through the inner cup. Mixtures consisting of oxidizer $\left(\mathrm{O}_{2}\right)$ and fire extinguishing agent $\left(\mathrm{N}_{2}\right)$ were issued through the outer chimney. The relative percentages of $\mathrm{O}_{2} / \mathrm{N}_{2}$ were varied, maintaining the total flow rate of $\mathrm{O}_{2}+\mathrm{N}_{2}$ constant. The $\mathrm{CO}$ concentration in the post-combustion mixture was measured as a function of the oxygen concentration. In the case of $\mathrm{CH}_{4}$ flame, the $\mathrm{CO}$ concentration was increased with decreasing $\mathrm{O}_{2}$ concentration. In contrast, in the case of $\mathrm{CH}_{3} \mathrm{OH}$, the $\mathrm{CO}$ concentration was decreased with decreasing $\mathrm{O}_{2}$ concentration. The results show that the influence of the oxygen concentration on the $\mathrm{CO}$ production yield in liquid combustion is apparently different from that of gaseous combustion.
\end{abstract}

KEYWORDS: carbon monoxide, compartment fires, oxygen concentration, toxicity, suppression, halon replacement

\section{NOMENCLATURE}

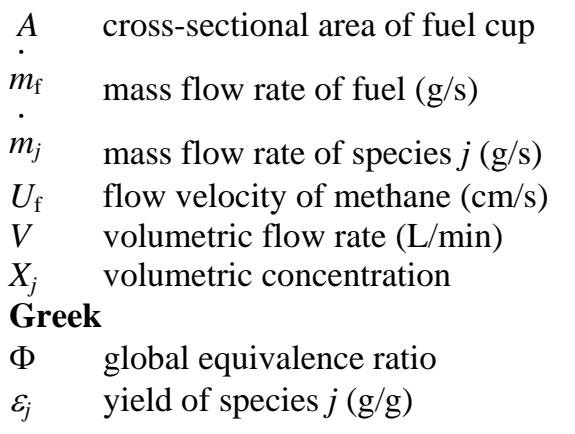

\author{
Subscripts \\ f fuel \\ i inert component \\ j chemical species \\ m oxygen and inert mixture \\ o oxygen \\ stoich stoichiometric condition \\ system actual condition
}

\section{INTRODUCTION}

Reduced oxygen concentration environment is utilized for a wide variety of purposes, from the fire and explosion prevention to the athletic training rooms. Following the ban of halon production, the inert gas fire extinguishing systems have also come into wide use in the context of the spread of electronic devices and the request for eliminating the damage by water. Furthermore, the nitrogen-enriched air, which is produced from the 
ambient air using a gas separation membrane, is expected as one of the alternative fire prevention and extinguishing technologies [1]. To ensure the fire safety in such reduced oxygen concentration environment, it is necessary to understand the effect of the oxygen concentration on the behavior of compartment fires, particularly on the carbon monoxide (CO) production because $\mathrm{CO}$ is known as a major cause of fatalities in compartment fires.

It is well known that the $\mathrm{CO}$ production in compartment fires can be remarkably larger than that from open fires. There are two factors that can affect the $\mathrm{CO}$ production in compartment fires, ventilation and vitiation [2]. With respect to the effect of ventilation, extensive investigation has been done on compartment fires [3] and laminar jet diffusion flames [4] in the normal oxygen concentration condition. The previous investigation revealed that the $\mathrm{CO}$ production yield is governed by the global equivalence ratio, $\Phi$, that is defined as the fuel-to-air ratio normalized by the stoichiometric fuel-to-air ratio. Beyler $[5,6]$ demonstrated by hood experiments for a variety of fuels that the $\mathrm{CO}$ production yield shows an abrupt increase as $\Phi$ approaches a value of 1.0. Tewarson et al. [7] developed a correlation model for yields of combustion products including CO versus $\Phi$. Tanaka et al. [8] investigated the estimation method for the $\mathrm{CO}$ concentration in a methanol fire compartment. Using the measured fuel gasification rate, their results agreed well with those of Beyler. They also concluded that the difficulty in predicting the fuel gasification rate in a compartment is obstructing the predictability for the $\mathrm{CO}$ yield from liquid-fuel fires.

On the other hand, with respect to the effect of vitiation (oxygen depletion), we can find very few investigations in the literature. Tewarson et al. [9] investigated the influence of oxygen concentration on flame radiation and convection. Tsuchiya and Mathieu [10] reported that the $\mathrm{CO}$ yield from plywood was significantly increased at the transition from the flaming to the smoldering by decreasing the oxygen concentration. Sega and Sato [11] reported that the CO yield from smoldering wood was monotonically decreased with the decrease in the oxygen concentration. For the flaming fire plumes, however, the literature has yet to reach a generally accepted conclusion concerning the effect of oxygen concentration on the CO yield $[2,12,13]$.

The objective of the present study is to reveal the $\mathrm{CO}$ production characteristics in gaseous and liquid flaming combustion under reduced oxygen concentration environment. For this purpose, the cup-burner flames [14], which are most widely used in laboratory-scale fire suppression testing, are employed because it is easy to control the oxygen concentration precisely with well-controlled flow-field. The effect of oxygen concentration on the $\mathrm{CO}$ yield of cup-burner flames is investigated experimentally. The effects of oxygen concentration on the gasification rate and $\Phi$ for liquid fuel flames are also investigated using the cup burner. A comparison between the results of the present study and the previously demonstrated ventilation effect will then be discussed.

\section{EXPERIMENTAL}

\section{FRI Reduced-scale Cup Burner Apparatus}

Figure 1 shows the schematic illustration of the experimental set-up. Three important parts of the cup burner apparatus are the cup burner, the overflow-type liquid fuel reservoir with the fuel level control device, and the $\mathrm{O}_{2} / \mathrm{N}_{2}$ mixture and gaseous fuel supply system [14]. The cup burner is a coaxial diffusion flame burner. The inner cup and 
the outer chimney are Pyrex ${ }^{\mathrm{TM}}$ glass tubes. In the present study, the cup diameter of $10 \mathrm{~mm}$ was employed for gaseous fuel, while that of $13 \mathrm{~mm}$ was employed for liquid fuel in order to conduct the experiments under the same condition as the previous study [14]. The chimney diameter of $26 \mathrm{~mm}$ was employed for both gaseous and liquid fuels.

Methane $\left(\mathrm{CH}_{4}\right)$ and methanol $\left(\mathrm{CH}_{3} \mathrm{OH}\right)$ were used as gaseous and liquid fuels, respectively, both of which were supplied through the inner cup. Mixtures consisting of $\mathrm{O}_{2}$ and $\mathrm{N}_{2}$ were issued through the outer chimney. The flow rates of $\mathrm{O}_{2}$ and $\mathrm{N}_{2}$ as well as that of $\mathrm{CH}_{4}$ were controlled with mass flow controllers before introducing into the cup burner. The $\mathrm{O}_{2}$ and $\mathrm{N}_{2}$ flows were mixed in a mixing chamber and in the bed of glass beads at the bottom of the cup burner. The $\mathrm{O}_{2}$ concentration, $X_{0}$, in the $\mathrm{O}_{2}+\mathrm{N}_{2}$ mixture was varied, maintaining the total flow rate of $\mathrm{O}_{2}+\mathrm{N}_{2}$ constant.

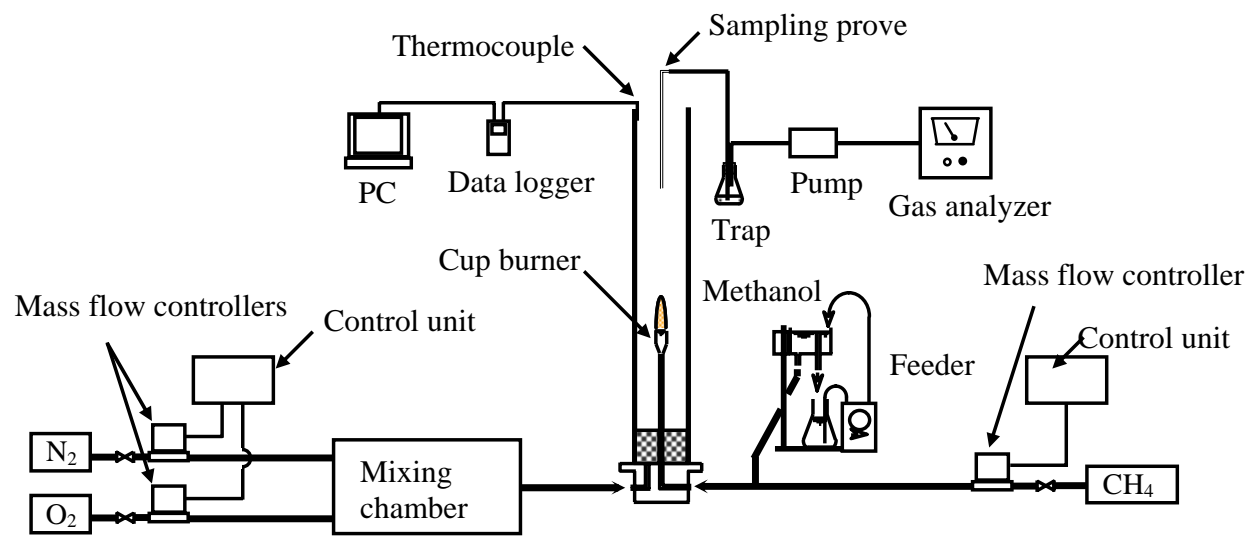

Fig. 1. Schematic illustration of the experimental set-up.

\section{Carbon Monoxide Concentration Measurement}

The gas sampling and analyzing systems are illustrated in Fig. 1. The gas sampling system consists of a $2 \mathrm{~mm}$ diameter stainless-steel tube with a thermocouple, that was followed by a water and particulate trap and a suction pump. The sampling of the postcombustion mixtures was conducted continuously through the sampling tube located along the centerline of the chimney. The gas flew through the trap and then went into the analyzing system.

The measurement of the $\mathrm{CO}$ concentration in the post-combustion mixtures was carried out with a non-disperse IR gas analyzer. To ensure the complete mixing of all the species in the post-combustion mixtures at the inlet of the sampling tube, the inlet of the sampling tube was located far enough from the flame where the uniformity of $\mathrm{CO}$ concentration was verified for both axial and radial directions. Gas temperature near the inlet of the sampling tube was also measured with a thermocouple, and was found to be approximately $100^{\circ} \mathrm{C}$, indicating that the $\mathrm{CO}$ oxidation reactions were already frozen at the sampling tube.

\section{Fuel Gasification Rate Measurement}

The experimental procedures for the measurement of the liquid fuel gasification rate are the same as that of our previous work [15]. An electronic balance was placed under the 
fuel reservoir, and the weight of the reservoir was recorded continuously by PC connected to the balance, during the burning period of 10 to 30 minutes with keeping the oxygen concentration constant. The vaporization loss of fuel at the reservoir was also measured by running the fuel feeder without burning the fuel. The fuel gasification rate at the cup burner, $m_{\mathrm{f}}$, is then obtained as the slope of the weight reduction curve for the burning test followed by the correction for the vaporization loss of fuel at the reservoir. The measurements of $m_{\mathrm{f}}$ were repeated at various oxygen concentrations.

\section{RESULTS AND DISCUSSION}

\section{Flame Behavior under Reduced Oxygen Concentration Environment}

Figure 2 shows the methane and methanol flame behavior under reduced oxygen concentration environment. For the methane flames, the flow velocity of methane at the cup exit $\left(U_{\mathrm{f}}\right)$ was $5 \mathrm{~cm} / \mathrm{s}$. For both flames the flow rate of the $\mathrm{O}_{2} / \mathrm{N}_{2}$ mixture $\left(V_{\mathrm{m}}=V_{\mathrm{o}}+\right.$ $V_{\mathrm{i}}, V_{\mathrm{o}}$ : the volumetric flow rate of $\mathrm{O}_{2}, V_{\mathrm{i}}$ : the volumetric flow rate of $\mathrm{N}_{2}$ ) was $2.0 \mathrm{l} / \mathrm{min}$. It is seen in Fig. 2 that both of methane and methanol flames exhibit reduced emission intensity with the decrease in the oxygen concentration, demonstrating the suppression effect of nitrogen that causes remarkable reduction in the flame temperature [16].

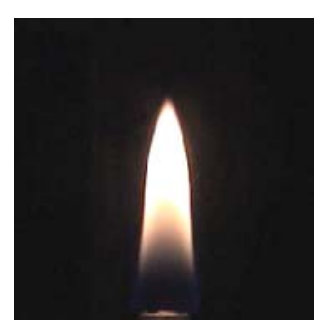

$X_{\mathrm{o}}=21 \%$

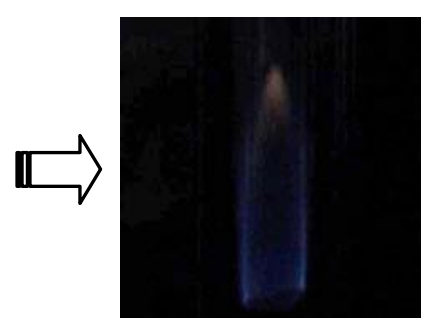

$X_{0}=17 \%$

$\mathrm{CH}_{4}$ flame

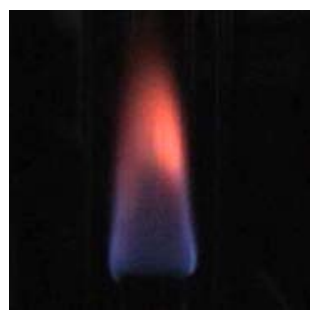

$X_{\mathrm{o}}=17 \%$

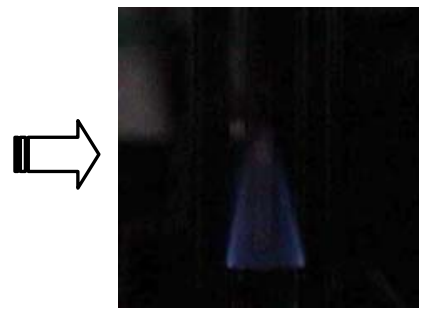

$X_{\mathrm{o}}=15 \%$

$\mathrm{CH}_{3} \mathrm{OH}$ flame

Fig. 2. Cup-burner flame behavior under reduced oxygen concentration environment. 
Table 1. CO concentrations measured under various oxygen concentrations.

\begin{tabular}{cccc}
$\mathrm{CH}_{4}$ flame $\left(U_{\mathrm{f}}=5 \mathrm{~cm} / \mathrm{s}, V_{\mathrm{m}}=2.0\right.$ & $1 / \mathrm{min})$ \\
\hline$X_{\mathrm{o}}(\%)$ & 21 & 19 & 17 \\
\hline$X_{\mathrm{co}}(\mathrm{ppm})$ & 1400 & 11800 & 12500 \\
\hline
\end{tabular}

\begin{tabular}{cccc}
\multicolumn{4}{c}{$\mathrm{CH}_{3} \mathrm{OH}$ flame $\left(V_{\mathrm{m}}=2.01 / \mathrm{min}\right)$} \\
\hline$X_{\mathrm{o}}(\%)$ & 17 & 16 & 15 \\
\hline$X_{\text {co }}(\mathrm{ppm})$ & 15600 & 8700 & 1600 \\
\hline
\end{tabular}

In terms of the flame height, however, the reduction in the oxygen concentration causes the opposite result between the methane and methanol flames. That is, the methane flame became longer whereas the methanol flame became shorter with the decrease in the oxygen concentration. The increased flame height for methane is a consequence of slower combustion reactions due to the reduced flame temperature. The decreased flame height for methanol is a consequence of slower fuel gasification, which is also due to the reduced flame temperature. The effect of oxygen concentration on the fuel gasification rate of methanol will be discussed later.

\section{Effect of Oxygen Concentration on the CO Yield}

Variation of the $\mathrm{CO}$ concentration $\left(X_{\mathrm{co}}\right)$ in the post-combustion mixture of methane and methanol flames with the decrease in the oxygen concentration $\left(X_{\mathrm{o}}\right)$ in the $\mathrm{O}_{2}+\mathrm{N}_{2}$ mixture is shown in Table 1 . Here, $U_{\mathrm{f}}$ is the mean axial flow velocity of $\mathrm{CH}_{4}$ at the top edge of the inner cup $\left(=V_{\mathrm{f}} / A\right)$, and $V_{\mathrm{m}}$ is the volume flow rate of $\mathrm{O}_{2}+\mathrm{N}_{2}$. As shown in Table 1, in the case of $\mathrm{CH}_{4}$ flame, $X_{\mathrm{co}}$ increases with decreasing $X_{0}$. In contrast, in the case of $\mathrm{CH}_{3} \mathrm{OH}$ flame, $X_{\text {co }}$ decreases with decreasing $X_{\mathrm{o}}$. This result shows that the effect of oxygen concentration on $\mathrm{CO}$ yield in gaseous combustion is apparently different from that in liquid combustion.

Figure 3 shows the variation of the $\mathrm{CO}$ yield as a function of the oxygen concentration in the $\mathrm{O}_{2}+\mathrm{N}_{2}$ mixture. Here the $\mathrm{CO}$ yield, $\varepsilon_{\mathrm{CO}}$, is defined as Eq. 1 using the total mass flow rate of $\mathrm{CO}, \dot{m}_{\mathrm{CO}}$, and the mass flow rate of fuel, $\dot{m}_{\mathrm{f}}[4]$.

$\varepsilon_{\mathrm{CO}}=\frac{\dot{m}_{\mathrm{CO}}}{\dot{m}_{\mathrm{f}}}$.

It is seen in Fig. 3 that the $\mathrm{CO}$ yield of methane flames is actually increased with the decrease in the oxygen concentration, whereas that of methanol flames is reduced with the decrease in the oxygen concentration. 


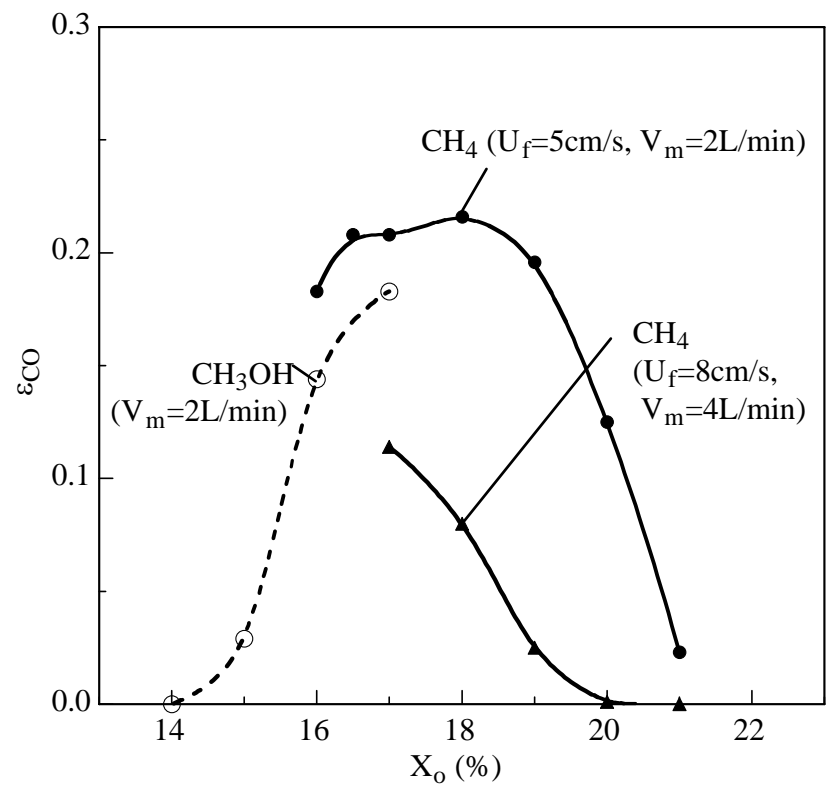

Fig. 3. Variation of the $\mathrm{CO}$ yield as a function of the oxygen concentration.

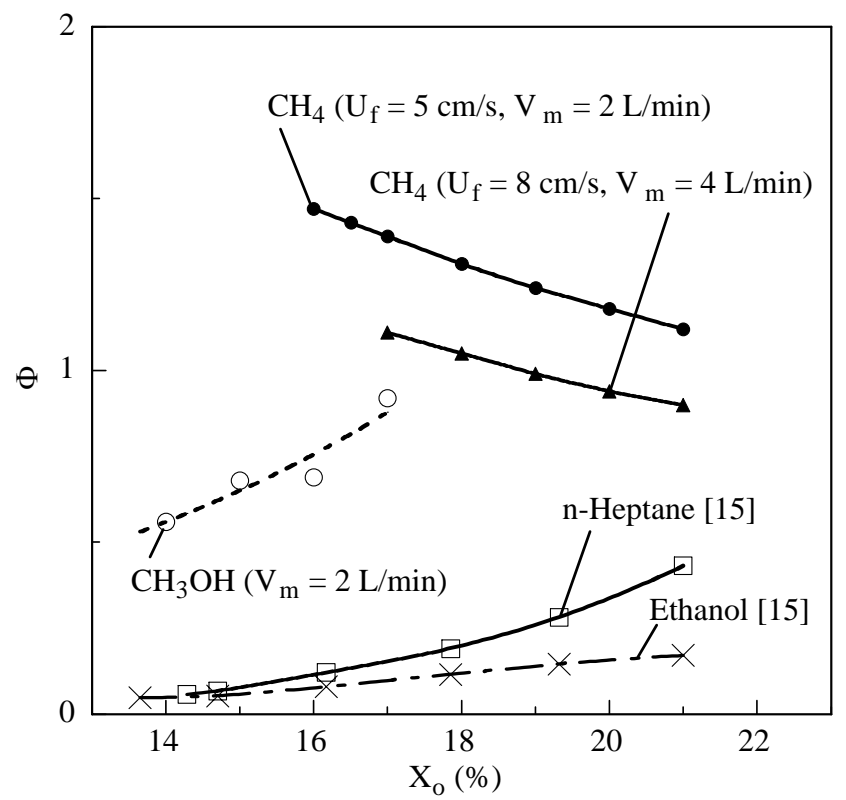

Fig. 4. Variation of the global equivalence ratio as a function of the oxygen concentration.

Marlair et al. [13] measured the $\mathrm{CO}$ yield for pyridine flames as a function of $\mathrm{O}_{2}$ concentration at constant values of $\Phi$, by adjusting the air flow rate. Their results show that the $\mathrm{CO}$ yield is increased with the decrease in the oxygen concentration, which is in contrast with the present methanol results. Because $V_{\mathrm{m}}$ is kept constant in the present 
work, $\Phi$ is not constant but varied with the variation in the oxygen concentration. Thus we next examine the influence of oxygen concentration on $\Phi$.

\section{Effect of Oxygen Concentration on the Global Equivalence Ratio}

Figure 4 shows the variation of $\Phi$ as a function of the oxygen concentration in the $\mathrm{O}_{2}+$ $\mathrm{N}_{2}$ mixture. $\Phi$ is defined as Eq. 2 using the volume flow rate of fuel, $V_{\mathrm{f}}$, and $V_{\mathrm{o}}$ for actual (subscript 'system') and stoichiometric (subscript 'stoich') conditions.

$$
\Phi=\left(\frac{V_{\mathrm{f}}}{V_{\mathrm{o}}}\right)_{\text {system }} /\left(\frac{V_{\mathrm{f}}}{V_{\mathrm{o}}}\right)_{\text {stoich }} \cdot
$$

$V_{\mathrm{f}}$ for the methanol flames was calculated from the measured fuel gasification rate, $\dot{m}_{\mathrm{f}}$, directly. Also plotted in Fig. 4 are the literature data for n-heptane and ethanol measured with the standard-size cup burner apparatus in which the cup diameter is $30 \mathrm{~mm}$ and the chimney diameter is $85 \mathrm{~mm}$, at a constant air flow rate of $401 / \mathrm{min}$ [15].

All the three liquid fuels in Fig. 4 show significant reduction in $\Phi$ with the decrease in the oxygen concentration, whereas methane shows remarkable increase in $\Phi$ with the decrease in the oxygen concentration. This result shows that the effect of oxygen concentration on $\Phi$ in gaseous combustion is again apparently different from that of liquid combustion. In the present study, both the methane flow velocity, $U_{\mathrm{f}}$, and $V_{\mathrm{m}}$ are kept constant when varying the oxygen concentration. Thus with the decrease in the oxygen concentration for methane flames, $\Phi$ necessarily increases. On the other hand, for the liquid fuel flames, it is difficult to predict the variation of $\Phi$ because the fuel gasification rate is dependent on the rate of heat transfer from the flame to the pool surface. The opposite effect of the oxygen concentration on the $\mathrm{CO}$ yield between gaseous- and liquid-fuel flames, that is demonstrated in Fig. 3, can be explained as a consequence of the reverse variation in the global equivalence ratio, which is increased with decrease in the oxygen concentration for the gaseous-fuel flames whereas decreased for the liquid-fuel flames due to the remarkable reduction in the fuel gasification rate.

The significant reduction in the fuel gasification rate with decreasing ambient oxygen concentration observed in the present study is consistent with experimental results for other fuels published by the previous workers [2,9,13,17,18]. For example, it was observed for polymethyl methacrylate (PMMA) pool by Santo and Tamanini [17]. They attributed their results primarily to the decrease in soot concentration, based on the observation that the flame radiation also decreased significantly. It is, however, known that the primary effect of nitrogen in fire suppression is the reduction in flame temperature [15]. Accordingly we suggest the reduced flame temperature as the primary cause of both the present liquid-fuel results and the PMMA results of Ref. 17.

We note that the apparent differences between gaseous fuel flames and liquid fuel flames shown in Figs. 3 and 4 are not inherent to the difference in the physical state of the fuel itself, but in physical laws governing diffusion flames. In the case of gaseous fuel flames, the flame behavior is solely determined by the gas flow introduced into the burner. In the case of liquid fuel flames, the flame behavior is self-regulated through the heat feedback from the flame to the pool surface, which governs the vaporization and/or pyrolysis of the fuel. As the heat feedback is clearly affected by the oxygen concentration, a more 
complex situation is taking place for liquid fuel flames that, in the present experiments, causes the results contrary to those for the gaseous fuels as shown in Figs. 3 and 4.

\section{Relationship between the CO Yield and the Global Equivalence Ratio}

We next examine the applicability of $\Phi$, that has been employed to describe the effect of ventilation on the $\mathrm{CO}$ yield, to the prediction of the $\mathrm{CO}$ yield under reduced oxygen concentration environment. Figure 5 shows the variation of the $\mathrm{CO}$ yield measured in the present study with varying the oxygen concentration, as a function of $\Phi$. Also plotted in Fig. 5 are the methane data reported by Leonard et al. [4], that were obtained at a constant oxygen concentration with varying the ventilation condition.

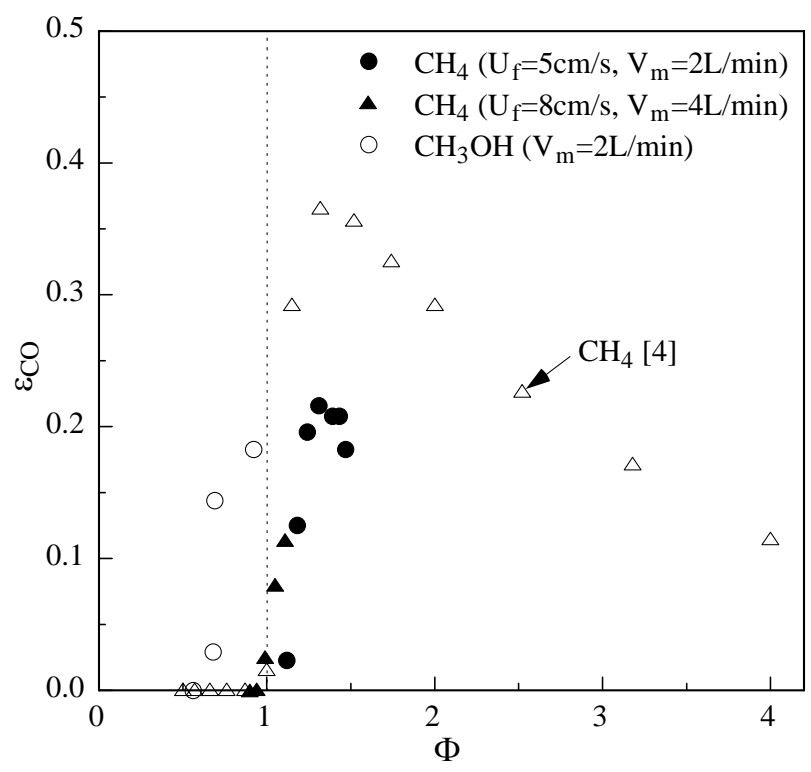

Fig. 5. Variation of the $\mathrm{CO}$ yield as a function of the global equivalence ratio.

It is seen in Fig. 5 that the CO yield measured in the present study exhibits abrupt increase near $\Phi=1$, regardless of the fuel type of gas or liquid. The results in Fig. 5 show that the effect of the oxygen concentration on the CO yield for both the gaseous- and liquid-fuel flames is qualitatively consistent with the previously-observed relationship between the $\mathrm{CO}$ yield and $\Phi$ varied with the ventilation condition at a constant oxygen concentration. It suggests that the ventilation effect and the vitiation effect on the $\mathrm{CO}$ yield in compartment fires are essentially the same. This implies that the $\mathrm{CO}$ yield under reduced oxygen concentration environment can also be predicted using the global equivalence ratio variation. However, these suggestions are rather speculative and have yet to be examined carefully. The previous experimental results for pyridine [13] showed that the $\mathrm{CO}$ yield varied remarkably even at a constant $\Phi$ when the $\mathrm{O}_{2}$ concentration was varied. It suggests that the velocity of the flow entrained into the flame would also affect the CO yield as well as the $\mathrm{O}_{2}$ concentration and $\Phi$. As it is impossible to vary the $\mathrm{O}_{2}$ concentration with both $\Phi$ and $V_{\mathrm{m}}$ kept constant in the present experiments, the conclusion can be only qualitative in the present stage. Recognizing that the inert component in the reduced oxygen concentration environment contributes to the reduction 
in the flame temperature, further investigation should be conducted for quantitative comparison between the ventilation effect and the vitiation effect.

\section{CONCLUSIONS}

To clarify the characteristics of the $\mathrm{CO}$ production in gaseous and liquid combustion under reduced oxygen concentration, the $\mathrm{CO}$ production yields under oxygen-reduced conditions were measured experimentally using a cup burner. The following conclusions were obtained:

1. In the case of gaseous-fuel flames, the $\mathrm{CO}$ yield is increased with decrease in the oxygen concentration. In contrast, in the case of liquid-fuel flames, the $\mathrm{CO}$ yield is decreased with decrease in the oxygen concentration.

2. The opposite effect of the oxygen concentration on the $\mathrm{CO}$ yield between gaseous- and liquid-fuel flames is a consequence of the reverse variation in the global equivalence ratio, which is increased with decrease in the oxygen concentration for the gaseous-fuel flames whereas decreased for the liquid-fuel flames due to the remarkable reduction in the fuel gasification rate.

3. The effect of the oxygen concentration on the $\mathrm{CO}$ yield for both the gaseous- and liquid-fuel flames is qualitatively consistent with the previously-observed relationship between the $\mathrm{CO}$ yield and the global equivalence ratio that was varied with the ventilation condition at a constant oxygen concentration. This implies that the $\mathrm{CO}$ yield under reduced oxygen concentration environment can also be predicted using the global equivalence ratio variation.

\section{ACKNOWLEDGMENT}

The authors thank Dr. Chihong Liao of the National Research Institute of Fire and Disaster of Japan for his helpful advices on the experimental technique.

\section{REFERENCES}

[1] Liao, C., "Feasibility of Gaseous Media Fire Prevention and Extinguishing System Using a Gas Separation Membrane," Journal of Japan Association for Fire Science and Engineering, 54, pp. 38-43, (2004), (in Japanese).

[2] Mulholland, G., Janssens, M., Yusa, S., Twilley, W., and Babrauskas, V., "The Effect of Oxygen Concentration on CO and Smoke Produced by Flames," Fire Safety Science - Proceedings of the Third International Symposium, International Association for Fire Safety Science, 1991, pp. 585-594.

[3] Pitts, W.M., "The Global Equivalence Ratio Concept and the Formation Mechanisms of Carbon Monoxide in Enclosure Fires," Progress in Energy and Combustion Science, 21, pp. 197-237, (1995).

[4] Leonard, S., Mulholland, G.W., Puri, R., and Santoro, R.J., "Generation of CO and Smoke During Underventilated Combustion," Combustion and Flame, 98, pp. 20-34, (1994).

[5] Beyler, C.L., "Major Species Production by Diffusion Flames in a Two-layer Compartment Fire Environment," Fire Safety Journal, 10, pp. 47-56, (1986). 
[6] Beyler, C.L., "Major Species Production by Solid Fuels in a Two Layer Compartment Fire Environment," Fire Safety Science - Proceedings of the First International Symposium, International Association for Fire Safety Science, 1986, pp. 431-440.

[7] Tewarson, A., Jiang, F.H., and Morikawa, T., "Ventilation-controlled Combustion of Polymers," Combustion and Flame, 95, pp. 151-169, (1993).

[8] Tanaka, S., Mizuno, K., and Hasemi, Y., "Study of Force-ventilated Fires by Model Experiments (vol. 2)," Proceedings of the Annual Meeting of the Japan Association for Fire Science and Engineering, 1990, pp. 37-40 (in Japanese).

[9] Tewarson, A., Lee, J.L., and Pion, R.F., "The Influence of Oxygen Concentration on Fuel Parameters for Fire Modeling," Proceedings of the Combustion Institute, 18, pp. 563-570 (1981).

[10] Tsuchiya, Y., and Mathieu, J.F., "Heat, CO and Smoke Release Rates of Plywood under a Depleted Oxygen Atmosphere: An Experimental Study Using an OSU Heat Release Rate Apparatus," Fire Safety Science - Proceedings of the Third International Symposium, International Association for Fire Safety Science, 1991, pp. 605-614.

[11] Sega, S. and Sato, K., "Study on Smoldering - Flame Transition of Solid Material," Bulletin of Japan Association for Fire Science and Engineering, 35, pp. 9-15, (1985) (in Japanese).

[12] Tsuchiya, Y., " $\mathrm{CO} / \mathrm{CO}_{2}$ Ratios in Fire as a Function of Oxygen Concentration and Equivalence Ratio," Proceedings of the Annual Meeting of the Japan Association for Fire Science and Engineering, 1995, pp. 242-245, (in Japanese).

[13] Marlair, G., Bertrand, J.-P., and Brohez, S., "Use of the ASTM E 2058 Fire Propagation Apparatus for the Evaluation of Under-Ventilated Fires," Proceedings of the Fire and Materials Conference, January 2001, pp. 301-313.

[14] Saso, Y., Saito, N., and Iwata, Y., "Scale Effect of Cup Burner on FlameExtinguishing Concentrations," Fire Technology, 29, pp. 22-33, (1993).

[15] Saso, Y., Saito, N., Liao C., and Ogawa, Y., "Extinction of Counterflow Diffusion Flames with Halon Replacements," Fire Safety Journal, 26, pp. 303-336, (1996).

[16] Saso, Y., Joboji, H., Koda, S., Saito, N., and Nishioka, M., "Response of Counterflow Diffusion Flame Stabilized on a Methanol Pool to Suppressant Doping," Proceedings of the Combustion Institute, 28, pp. 2947-2955, (2000).

[17] Santo, G., and Tamanini, F., "Influence of Oxygen Depletion on the Radiative Properties of PMMA Flames," Proceedings of the Combustion Institute, 18, pp. 619-631, (1981).

[18] Peatross, M.J., and Beyler, C.L., "Ventilation Effects on Compartment Fire Characterization," Fire Safety Science - Proceedings of the Fifth International Symposium, International Association for Fire Safety Science, 1997, pp. 403-414. 